\section{SOI: 1.1/TAS DOI: 10.15863/TAS International Scientific Journal Theoretical \& Applied Science}

p-ISSN: 2308-4944 (print)

e-ISSN: 2409-0085 (online)

Year: 2017

Issue: 02

Volume: 46

Published: 15.02 .2017

http://T-Science.org

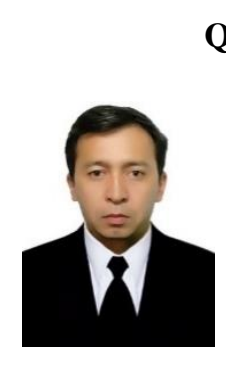

Qahramonjon Anvarjonovich Davronov

Ph.D.,

Agricultural production, storage and processing technology department, Fergana Polytechnic Institute jamol_qambarov@mail.ru

Odiljon Ibragimov PHD, Agricultural production,
cessing technology department Fergana Polytechnic Institute jamol_qambarov@mail.ru

SECTION 23. Agriculture. Agronomy. The technique.

\title{
THE EFFECTIVENESS OF THE USE OF LIQUID NITROGEN- FERTILIZER CALCIUM TO PREVENT THE ELEMENTS OF THE CROP
}

Abstract: For the purpose of the use of additional technical measures to accelerate the growth and development of cotton, increasing productivity and reducing the elements of shedding were studied terms and norms of application "LACF" liquid nitrogen-calcium as a top dressing over the leaves.

Research work conducted in the years 2014-2016 have shown an increase in the amount of shedding and reduced crop elements (inflorescence buds, cotton bolls) after applying "LACF" liquid nitrogen-calcium with the norm of 5, 10, 15, $20 \mathrm{l} / \mathrm{ha}$ at the time when 3-4 true leaves and full flowering (budding).

Key words: elements of the crop, shedding, cotton fertility, liquid nitrogen fertilizer, productivity of cotton plant, liquid nitric fertilizers, "LNCF" (liquid nitric calcium fertilizer).

Language: English

Citation: Davronov QA, Ibragimov OO (2017) THE EFFECTIVENESS OF THE USE OF LIQUID NITROGEN-FERTILIZER CALCIUM TO PREVENT THE ELEMENTS OF THE CROP. ISJ Theoretical \& Applied Science, 02 (46): 29-32.

Soi: http://s-o-i.org/1.1/TAS-02-46-6 Doi: crossef https://dx.doi.org/10.15863/TAS.2017.02.46.6

\section{Introduction}

In the agricultural sector of the Republic of Uzbekistan achieved great success in the development, application and implementation of appropriate research and development of innovative agricultural technologies on the cultivation of fertile crop and quality of cotton and wheat (Mirzajanov 2010, Abdualimov 2007, Tojiyev 2007).

Currently, for the production of liquid fertilizer and the timing and rules on the use of them for cotton cultivation, defined management research based on the findings and conclusions of experiments conducted in field hospitals and laboratories.

Based on this, we have set ourselves to the aim of studying the impact of the growth, the development of the quality of the cotton crop, by feeding leaves of cotton through the newly developed liquid nitrogen- fertilizer calcium in the Republic of Uzbekistan.

\section{Materials and Methods}

As is known, to the phase of budding and flowering cotton plant grows very slowly. Especially the slow growth observed during the intermediate phase of occurrence of these first, second, third and fourth leaves. Also in this period, they are very vulnerable and easily exposed to various diseases. And along with this, cotton needs feeding fertilizers, especially nitrogen and phosphorus.

Years of experience proved that it was in this period, feeding cotton bymeans of suspension NPK fertilizers through the cotton plant has a positive effect on the subsequent development of cotton, it accelerates the ripening and affect the overall growth of productivity (B.Tillabekov B.Niyazaliev 2010). In the developed countries raising cotton, feeding cotton with liquid suspensions through the lives is widely used.

But in Uzbekistan, due to the climatic conditions, and the status of cultivated land to use liquid fertilizer, you first need to determine the suitability, timing and norms. In this research, we first started working on the definition of standards for the application of liquid nitrogen-calcium fertilizer during the emergence of 3-4 true leaves and flowering phase.

Therefore, the main objectives of our work, we have identified the study of agricultural measures definition of acceptable terms and standards for the application of a new, long-term liquid nitrogencalcium fertilizer produced at the enterprise of JSC "Fergana Nitrogen" through the leaves, for the 
growth and development of cotton, accelerate budding (flowering) and reduce their shedding, as well as to determine the exact guidance to farmers on the use of this technology.

The research work carried out at the Department of the cultivation, storage and primary processing of agricultural products, as well as CBSPARI Ferghana scientific experimental station in 2014-2016 years, based on experiments carried out in laboratory and field conditions.

The observations and laboratory analyses, during tests carried out on the basis of a methodological guide "study guide UzPITI" (2007) and "The insecticide, acaricide, biologically active substances and guidelines to try and Fungicides" (1994) was carried out using.

In 2014, in the experimental fields were sown the seeds of varieties of cotton C-6524. During the experiment, for the controlled (not of the treatment) embodiment, comparing it with a urea-treated with standard $7 \mathrm{~kg} /$ ha embodiment, application rates were studied "LNCF" liquid nitrogen-calcium norm 5, 10, 15, 20 1/ha.

Field experiments were conducted at the Fergana scientific and experimental station CBSPARI, of Fergana conducted on the basis of agro-technical measures taken at the experimental farm of the foundation.

During the experiments, laboratory studies and phenological observations were carried out on research options. After thinning and at the end of the growth period of seedlings of cotton density was determined. phenological and biometrical observations were made on the growth of cotton, the number of fertile twigs, buds, inflorescences, cotton boxes, opened boxes and fallen buds.

At the same time, by the front surface of the leaves were there chcked out laboratory research, dry weight, photosynthesis productivity, yield and quality of cotton fiber.

On the experimental fields in cotton growth period the following works were carried out: 1 time thinning 2 times loosening of the soil, 4 times treatment bohveen the ranges 3 times watering, fertilizing, in the period of the appearance of 3-4 true leaves and full of budding (flowering) treatment and 3 times of seedlings with liquid nitrogen, calcium "LNCF".

As a result of agricultural mocesses on the use of liquid nitrogen-fertilizer calcium through the cotton leaves, on the basis of the studied variants were proven positive impact of this method on cotton growth. Namely, the 2014 year, the work on the application "LNCF" liquid nitrogen-calcium norm $5,10,15,201 /$ ha during budding (Flowering) of cotton, were held for 16 days.

At the result of the application through the leaves of liquid nitrogen-calcium "LNCF", observed disease resistance and resistance to insect pests, as well as free and healthy plant growth. Phenological observations were carried out in the period from June 1 to July $15,2014$.

On July 15 cotton growth was $71.8 \mathrm{~cm}, 12.2$ $\mathrm{cm}$ fruitful branches, the number of buds reached 10.1, 2.2 inflorescences, cotton bolls was 3.3 pc., After the application of the "SAKY̆" liquid nitrogencalcium norm 5,10, 15, $201 /$ ha, cotton growth reached $72,4-77,5 \mathrm{~cm}$, which is $0,6-5,7 \mathrm{~cm}$. higher than in embodiments where it is not used "LNCF".

Also there was observed an increase in the number of elements of the crop (inflorescence buds, cotton bolls) after applhaving ied "LNCF" liquid nitrogen-calcium with the norm of 5, 10, 15, $201 /$ ha.

During the experiments, mainly observed variants of plant growth and development, its height, the number of productive branches, increasing the filling elements of the harvest as a result of the use of liquid nitrogen-calcium "LNCF" with the norm, 5-10 1/ha.

Subsequent observations have shown that if the above mentioned laws, showed an increase in pilot version of cotton amounted to $81,4-90,5 \mathrm{~cm}$, the number of productive branches reached to $13,2-14,6$ pieces, and cotton bolls 10.5-12.5 pc . When using liquid nitrogen-calcium "LNCF" during flowering and budding (flowering) growth experienced option increased by $9.1 \mathrm{~cm}$, the number of productive branches by $1.4 \mathrm{pc}$, cotton bolls by $2.2 \mathrm{pc}$., And inflorescences 1,5 pieces.

The impact on growth and development cotton of liquid nitrogen-calcium "LNCF".

Table 1

\begin{tabular}{|l|l|c|c|}
\hline Morphological indices of plants & Norms "LNCF" 1/ha. & \multicolumn{2}{|l|}{ Indicators during experiments } \\
\cline { 3 - 4 } & & 1.08 .2014 & 1.08 .2015 \\
\hline Rate of grouth of the plant, cm & Control-0 & 81,4 & 90,4 \\
\cline { 2 - 4 } & Standard (suspension - NPK) -7 & 87,2 & 92,2 \\
\cline { 2 - 4 } & "LNCF" - 5 & 79,7 & 91,2 \\
\cline { 2 - 4 } & "LNCF" - 10 & 78,4 & 95,4 \\
\cline { 2 - 4 } & "LNCF" - 15 & 87,6 & 99,1 \\
\hline
\end{tabular}




\section{Impact Factor:}

\begin{tabular}{ll|lr} 
ISRA $($ India) $=\mathbf{1 . 3 4 4}$ & SIS $($ USA) & $=\mathbf{0 . 9 1 2}$ \\
ISI $($ Dubai, UAE) $=\mathbf{0 . 8 2 9}$ & PИНЦ (Russia) $=\mathbf{0 . 2 3 4}$ \\
GIF (Australia) $=\mathbf{0 . 5 6 4}$ & ESJI $($ KZ) & $=\mathbf{1 . 0 4 2}$ \\
JIF & $=\mathbf{1 . 5 0 0}$ & SJIF $($ Morocco $)=\mathbf{2 . 0 3 1}$
\end{tabular}

\begin{tabular}{|c|c|c|c|}
\hline & "LNCF" - 20 & 85,6 & 99,2 \\
\hline \multirow{6}{*}{$\begin{array}{l}\text { The quantity of fruitful } \\
\text { branches, pieces. }\end{array}$} & Control-0 & 13,2 & 13,3 \\
\hline & Standard (suspension - NPK) -7 & 14,0 & 14,0 \\
\hline & "LNCF" - 5 & 14,0 & 14,4 \\
\hline & "LNCF" - 10 & 13,9 & 13,9 \\
\hline & "LNCF" - 15 & 13,1 & 14,0 \\
\hline & "LNCF" - 20 & 12,1 & 14,6 \\
\hline \multirow{6}{*}{$\begin{array}{l}\text { The quantity of cotton bolls, } \\
\text { pieces. }\end{array}$} & Control-0 & 10,5 & 13,5 \\
\hline & Standard (suspension - NPK) -7 & 11,6 & 14,0 \\
\hline & "LNCF" - 5 & 13,0 & 14,7 \\
\hline & "LNCF" - 10 & 13,2 & 16,6 \\
\hline & "LNCF" - 15 & 12,7 & 17,3 \\
\hline & "LNCF" - 20 & 12,7 & 12,1 \\
\hline \multirow{6}{*}{$\begin{array}{l}\text { The quantity of dead buds, } \\
\text { pieces. }\end{array}$} & Control-0 & 3,6 & 4,3 \\
\hline & Standard (suspension - NPK) -7 & 2,4 & 3,2 \\
\hline & "LNCF" - 5 & 2,0 & 2,3 \\
\hline & "LNCF" - 10 & 2,2 & 2,4 \\
\hline & "LNCF" - 15 & 2,6 & 2,8 \\
\hline & "LNCF" - 20 & 3,0 & 3,2 \\
\hline
\end{tabular}

The conducted experiments in 2015, also showed improvement in the growth, development and fertility of cotton, in embodiments to which the "LNCF" liquid nitrogen-calcium was appleied. When growing and development of cotton were stored patterns 2014 and the application of liquid "LNCF" nitrogen-calcium normally 5-10 1/ha, there was an increase of productivity elements.

Based on the above mentioned research findings and experiences, it can be said that for increasiy the yield of elements and preventing the shedding of buds and bolls, the use of one of farming and measures, namely conducting feeding through the leaves of great importance. At the same time, the use of liquid nitrogen-calcium "LNCF" normally 5$101 /$ ha as a top dressing over the leaves, during the emergence of 3-4 true leaves, and during budding, accelerates growth and development of cotton in the initial stage, it will fit shedding elements yields and achieved high yield.

\section{Conclusions}

$\square$ the effectiveness of the use of liquid nitrogen for cotton-calcium "LNCF" with the norm of $5,10,15,201 /$ ha has been examined.

$\square$ during the period of the appearance of 3-4 true leaves, and in the budding stage (Bloom) increase the use of standards "LNCF" liquid nitrogen, calcium has a negative impact on growth, development and increased productivity elements;.

$\square$ when applied to cotton "LNCF" liquid nitrogen, calcium rate of $5 \mathrm{l} / \mathrm{ha}$ - in the period of the appearance of 3-4 true leaves and with the norm of 10 1/ha in the phase of budding and flowering, high productivity has been achieved;

$\square$ the use of liquid nitrogen for cotton-calcium "LNCF" shriveled leaves decreases in the initial period of growth, increases resistance to pests, increasing the number of elements yields.

\section{References:}

1. Gregorczyk A, Raczyńska A (1997) Study of the correlation between Arnon's method and measurements of chlorophyll content using a chlorophyll meter. Folia Universitatis Agriculture Stetinesis 181

2. (1994) Insecticide, acaricide, biologically active substances and guidelines to try and Fungicides. Tashkent, 1994, 102 p.

3. Niu G, Rodriguez DS (2006) Relative of salt tolerance of selected herbaceous perennials and groundcovers. Scientia Received April, 9, 2015; accepted for printing December, 23, 2015 Horticulture, 110: 352-358.

4. Odorova A, Asakawa S, Aikoh T (2004) Preferences for and attitudes towards street flowers and Teres in Sapporo, Japan. Landscape and Urban Planning, 69: 403-416.

5. Abdualimov S, Abdullaev F (2010) Gumimaks effective stimulators // rich harvest of agricultural crop production, resource and 


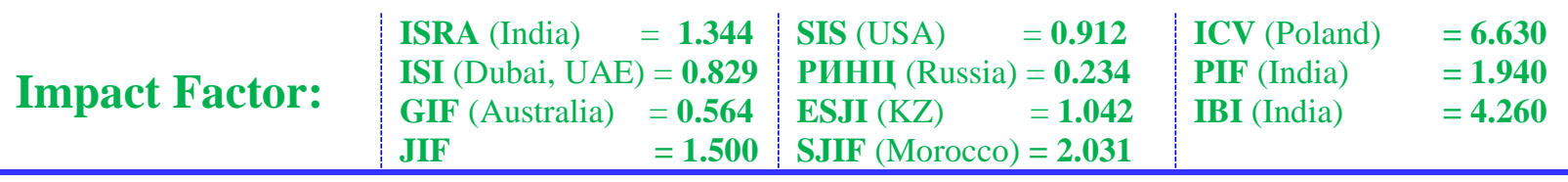

water-saving technologies. Collection of articles in the international scientific-practical conference. UzPITI. Tashkent, 2010. -p.233236.

6. (2007) The field of experimental methods. UzPITI. Tashkent, 2007, 147 p.

7. Vu DT, Tang C, Armstrong RD (2008) Changes and availability of $\mathrm{P}$ fractions following 65 years of $\mathrm{P}$ application to a calcareous soil in a Mediterranean climate // Plant and Soil. - 2008. - V. 304. - p. 21-33.

8. Warcholińska A, Fortuna - Antoszkiewicz B (2011) The use of flora in seasonal decorations of Urban public space based on the example of The Royal Rote in Warsaw. Annals of Warsaw
University of Life Sciences - SGGW. Horticulture and Landscape Architecture, 32: 53-61.

9. Zapata F, Roy RN (2004) Use of phosphate rocks for sustainable agriculture/ FAO Fertilizer and Plant Nutrition Bulletin. - Rome, Italy. 2004. - №13.

10. Zapryanova N, Atanassova B (2009) Effects of salt stress on growth and flowering of ornamental annual species. Biotechnology and Biotechnological Equipment, 23: 177-179.

Abreviations: 1/ha - litr hacters of, LNCF - liquid nitric calcium fertilizer. CBSPARI - Cotton Breeding, Seed Production And Agrotechnologies Research Institute 